\title{
ASSOCIATIVISMO GINÁSTICO E ESCOTISMO NO RIO GRANDE DO SUL \\ (1913-1934)
}

Evelise Amgarten Quitzau ${ }^{1}$

\section{RESUMO}

As sociedades ginásticas teuto-brasileiras foram um espaço de sociabilidade e educação da juventude no início do século XX, buscando contribuir para a formação física, moral e intelectual de seus associados, e para a preservação da cultura alemã no Brasil. A partir de 1913, no Rio Grande do Sul, estas associações adotam o escotismo como uma de suas práticas. O objetivo do artigo é analisar a organização do escotismo no âmbito destas associações e compreender o diálogo estabelecido entre ginástica e escotismo como meios de educação da juventude teutobrasileira no início do século XX. É possível perceber que neste âmbito o escotismo se desenvolveu paralelamente a outras iniciativas similares do período, mantendo um vínculo muito mais forte com instituições alemãs do que com as brasileiras.

Palavras-chave: escotismo, associativismo, sociedades de ginástica, história da ginástica.

${ }^{1}$ Universidad de la República (Udelar), Instituto Superior de Educación Física (Isef), Centro Universitario Regional Litoral Norte - Sede Paysandú (CUP), Paysandú, Uruguai. 


\section{ASOCIACIONISMO GIMNÁSTICO Y SCAUTISMO EN RIO GRANDE DO SUL (1913-1934)}

\section{RESUMEN}

Las sociedades gimnásticas alemán-brasileñas fueron un espacio de sociabilidad y educación de la juventud en el siglo XX, buscando contribuir para la formación física, moral e intelectual de sus miembros y para la preservación de la cultura alemana en Brasil. A partir de 1913, en Rio Grande do Sul, estas asociaciones adoptan el scautismo como una de sus prácticas. Este artículo busca analizar la organización del scautismo en en el ámbito de estas asociaciones y comprender el diálogo entre gimnástica y scautismo como medios de educación de la juventud alemán-brasileña en el inicio del siglo XX. Se percibe que en este ámbito el scautismo se desarrolló paralelamente a otras iniciativas similares del período, manteniendo un vínculo mucho más fuerte con instituciones alemanas que brasileñas.

Palabras clave: scautismo, asociacionismo, sociedades gimnásticas, historia de la gimnasia.

\section{GYMNASTICS SOCIETIES AND SCOUTISM IN RIO GRANDE DO SUL (1913-1934)}

\section{ABSTRACT}

German-Brazilian gymnastics societies represented a space for sociability and education of the youth in the first decades of the $20^{\text {th }}$ century. They aimed at contributing to the physical, intellectual and moral development of their associates and to the preservation of German culture in Brazil. From 1913 on, in Rio Grande do Sul, they adopt scoutism as one of their practices. This study aims at analyzing the organization of scoutism within these societies in Rio Grande do Sul, trying to comprehend the dialog they established between gymnastics and scoutism as means for youth in the first decades of the $20^{\text {th }}$ century. They developed scoutism in parallel with other similar initiatives of the period, keeping a much closer connection to German institution than to Brazilian ones.

Keywords: scoutism, associations, gymnastics societies, history of gymnastics.

\section{ASSOCIATIVISME GYMNASTIQUE ET SCOUTISME DANS LA REGION SUD DU BRESIL - RIO GRANDE DO SUL (1913-1934)}

\section{RÉSUMÉ}

Les sociétés gymnastiques teuto-brésiliennes furent un lieu important de sociabilité et d'éducation de la jeunesse au début du vingtième siècle. Elles souhaitaient contribuer à la formation physique, morale et intelectuelle des associés ainsi que préserver la culture allemande au Brésil à partir de la pratique de la gymnastique liée à d'autres exercices physiques en plein air. Débutant en 1913, un mouvement particulier fut observé entre les associations de la région, l'adoption du scoutisme comme une des pratiques et sa liaison à des unités scoutes allemandes. 
L'objectif de cet article est d'analyser l'organisation du scoutisme dans l'associativisme gymnastique teuto-brésilien rio-grandense et comprendre le dialogue établi entre la gymnastique et le scoutisme comme moyens d'éducation de la jeunesse du début du vingtième siècle.

Mots-clés: scoutisme, associativisme, sociétés de gymnastique, histoire de la gymnastique. 


\section{INTRODUÇÃO}

Nos últimos anos, o escotismo vem se tornando um tema recorrente entre os estudos sobre história da educação no Brasil (HEROLD JUNIOR; MELO, 2018; HEROLD JUNIOR; VAZ, 2016; 2015; 2012; HEROLD JUNIOR, 2016; 2013; 2011; OLIVEIRA; MÉNDEZ, 2015; RABELO; BARRETO, 2013; NASCIMENTO, J. C. 2008; NASCIMENTO, A., 2004; SOUZA, 2000). De maneira geral, estes estudos tomam o escotismo como um tipo de associação voluntária (RABELO; BARRETO, 2013) que exerceu um importante papel na formação da juventude brasileira, especialmente nas duas primeiras décadas após sua chegada ao país. Seja em vínculo com instituições escolares ou como uma iniciativa educativa marcadamente afastada do âmbito escolar, o escotismo representou um importante objeto de interesse de diferentes grupos e indivíduos interessados na formação da infância e da juventude: Herold Junior e Melo (2018), por exemplo, recentemente se debruçaram sobre uma série de indícios das relações entre escoteiros e clubes esportivos na cidade do Rio de Janeiro nas primeiras décadas do século $\mathrm{XX}$, analisando as articulações entre esporte e escotismo como práticas de formação da juventude carioca. No presente artigo, buscamos compreender como o escotismo foi tomado como um elemento educativo por uma instituição específica: as sociedades ginásticas teutobrasileiras, especialmente aquelas concentradas no Rio Grande do Sul.

Durante o século XIX e as primeiras décadas do século XX, o Brasil se tornou destino de milhares de indivíduos que deixaram seus países de origem por distintas razões. Entre estes diferentes grupos, os alemães se destacam não pela quantidade de indivíduos ${ }^{2}$, mas por terem sido um dos primeiros grupos a chegar ao país (a primeira colônia foi criada no Rio Grande do Sul, em 1824, logo nos primeiros anos de estabelecimento de uma política migratória) e pela rede de associações que criaram nas regiões onde se instalaram. Como outros grupos de imigrantes, trouxeram consigo práticas, crenças e costumes que buscaram

\footnotetext{
2 Segundo Willems (1980), os indivíduos identificados como alemães correspondiam a $7 \%$ dos 4.097.783 imigrantes que entraram no país no período entre 1887 e 1936.
} 
cultivar no novo país, e as associações foram um importante espaço para sua preservação, disseminação e mesmo adaptação nesta nova realidade.

A densa rede associativa que se observa nas áreas de colonização alemã começou a se formar a partir de meados do século XIX e ganhou força a partir da década de 1880, quando um maior número de imigrantes oriundos de áreas urbanizadas e com níveis mais elevados de formação passaram a se instalar nas colônias, especialmente naquelas situadas no meio urbano. Em meio às distintas sociedades por eles organizadas, as classificadas como "recreativas" (SEYFERTH, 1999) estavam entre as mais numerosas destacando-se entre elas as sociedades ginásticas (Turnvereine).

As primeiras sociedades ginásticas teuto-brasileiras foram fundadas em Joinville e no Rio de Janeiro, no final da década de 1850. Entretanto, assim como o associativismo teuto-brasileiro de maneira mais ampla, somente a partir dos anos 1880 observa-se uma intensificação no crescimento deste tipo de associação, especialmente na região Sul do país, que, segundo levantamento de 1932, agrupava o maior número de sociedades desse tipo. Das 57 sociedades apontadas neste levantamento, 22 estavam no Rio Grande do Sul e 20 em Santa Catarina (DIE T. R. G. ZUM AUSLANDE, 1932).

Uma análise dos estatutos destas sociedades revela que seu objetivo era o fortalecimento físico, moral e espiritual de seus associados por meio da prática do Turnen, método ginástico criado por Friedrich Ludwig Jahn na Alemanha, no início do século XIX. Apresentavam um cotidiano dinâmico, com sessões de ginástica à noite, durante a semana, e, aos finais de semana, com passeios junto à natureza e encontros em suas praças de jogos, locais ao ar livre onde podiam praticar corridas, saltos, nado, lançamentos, arremessos e distintos jogos que foram paulatinamente incorporados pelos ginastas, como o punhobol, o Tamburinball, o handebol e o futebol. Todavia, compreendendo-se como "postos avançados da germanidade no exterior”, estas associações não se limitavam a atividades puramente corporais, buscando oferecer também apresentações teatrais, bibliotecas e encontros musicais, majoritariamente em alemão, com o 
objetivo de contribuir para a preservação da língua e da cultura alemã no país que os recebera (QUITZAU, 2011; 2016).

Ao longo das oito décadas em que estas associações atuaram de maneira praticamente ininterrupta em nosso país, é possível perceber uma preocupação recorrente com a educação da juventude teuto-brasileira, visível na publicação de distintos textos que exaltavam a importância da prática de exercícios físicos pelas crianças e jovens e a necessidade de educá-los desde cedo neste ambiente, para que, quando adultos, continuassem os esforços pela manutenção e disseminação do Turnen e, mais amplamente, da germanidade. Neste sentido, era comum que estas associações oferecessem suas instalações para que as escolas alemãs da cidade levassem seus alunos, nos dias e horários em que não eram utilizadas por seus associados (como era o caso da Turnerschaft von 1890 in São Paulo), ou mesmo assumissem as aulas de ginástica oferecidas nestas instituições escolares (como acontecia com a Turnerbund Porto Alegre, cujos professores de ginástica também davam aulas para os alunos das escolas alemãs da cidade).

Independentemente de terem uma conexão com as escolas alemãs locais, estas associações mantinham departamentos específicos para jovens e crianças, geralmente divididos entre meninos e meninas. Eram frequentes em suas publicações textos que exaltavam a prática do Turnen e dos exercícios físicos ao ar livre pelos jovens e exortavam seus associados a levarem seus filhos para suas sociedades, como fazia a Teuto-Brasilianischer Turnverein Curitiba ao pedir a seus membros que "deixem nossa juventude se fortalecer na aula de ginástica, viver ao ar livre, na luz e no sol, pois nossas crianças são o maior bem da nação, elas são nossa esperança de um futuro melhor" (TEUTO-BRASILIANISCHER..., 1929, p. 8).

É comum observarmos nas sociedades ginásticas uma exaltação à vida ao ar livre, à prática de jogos e atividades em meio à natureza como um importante complemento à ginástica em seu objetivo de fortalecimento corporal, espiritual e moral da população teuto-brasileira, especialmente como um contraponto aos males oriundos da vida nas cidades em formação. Entretanto, as atividades 
oferecidas por estas associações variavam, e entre as particulares existentes destaca-se, no Rio Grande do Sul - nomeadamente em Porto Alegre, São Leopoldo, São Sebastião do Caí e Santa Cruz 3 -, o oferecimento e a organização do escotismo no âmbito das sociedades ginásticas, como um departamento com relativa autonomia, mas diretamente vinculado a estas associações, em um movimento que, conforme se pode observar pelas fontes, parece ter se desenvolvido apenas neste estado.

Segundo Herold Junior (2016; 2013) e Herold Junior e Vaz (2016; 2015; 2012), o escotismo foi um movimento iniciado pelo general inglês Robert Stephenson Smyth Baden-Powell em 1907. Ao criá-lo, Baden-Powell partia de uma crítica intensa à sociedade inglesa moderna e a seu sistema educativo, que se afastavam cada vez mais da natureza e buscavam apenas um desenvolvimento intelectual da juventude. Herold Junior e Vaz (2012), ao analisarem a educação corporal nos escritos de Baden-Powell, afirmam que

a mesma civilização vista como valiosa para ser "transmitida" como
modelo aos "incultos", também poderia se transformar em obliteradora
e cultivadora de vícios. Estes poriam em cheque a viabilidade de
existência da própria civilização, levantando dúvidas sobre a
possibilidade, a necessidade e o sucesso de sua "transmissão". Por isso,
gestado em um movimento expansivo da "civilização europeia", o
escotismo foi importante por lutar contra os efeitos negativos trazidos
por esses valores, deles cuidando por se assumir como justificáveis os
interesses de um país de ambições imperiais (HEROLD JUNIOR; VAZ,
2012, p. 167).

Expressão do ímpeto imperialista e colonialista inglês de fins do século XIX (MÉNDEZ; SCHARAGRODSKY, 2016), mas, principalmente, de um período em que uma série de movimentos da juventude começam a ser organizados (SELTEN, 1996) e um ideário de vida ao ar livre começa a ganhar força como contraponto à vida nas cidades, o escotismo se compreendia como um sistema

3 Estas são as sociedades em que, na documentação pesquisada, encontramos referências ao escotismo. 
educativo complementar ao escolar, em que o contato direto com a natureza contribuiria para o fortalecimento físico e moral da juventude, conquistando rapidamente grande quantidade de adeptos em diferentes países, inclusive o Brasil, onde aportou no ano de 1910, com a criação do Centro Brasileiro de Boys Scout, no Rio de Janeiro (OLIVEIRA; MÉNDEZ, 2015), onde rapidamente foi incorporado por diferentes clubes esportivos (HEROLD JUNIOR; MELO, 2018).

No que diz respeito ao escotismo vinculado às sociedades ginástica teutobrasileiras, apesar de ser aparentemente localizado no Rio Grande do Sul, e limitado a algumas sociedades, este movimento se tornou bastante organizado, chegando-se à fundação de uma Liga de Escoteiros Teuto-Brasileiros do Rio Grande do Sul (Deutschbrasilianischer Pfadfinderbund für Rio Grande do Sul), à sua incorporação à Deutscher Pfadfinderbund (Liga dos Escoteiros Alemães) e não à Associação Brasileira de Escoteiros (1914) - e à publicação de um periódico próprio, intitulado Am Lagerfeuer, o que nos fornece um indício da importância que este movimento tomou no âmbito do associativismo ginástico teuto-brasileiro neste estado. Neste sentido, cabe-nos perguntar: de que maneira o escotismo se vinculava ao Turnen na educação da juventude teuto-brasileira nestas associações? Se os jogos e as caminhadas junto à natureza já eram práticas comuns nestas sociedades ginásticas, por que adotar o escotismo? Considerandose que estas associações estavam em constante contato com a organização do Turnen e seus desenvolvimentos na Alemanha, de que maneira a Deutsche Turnerschaft, entidade alemã à qual as sociedades teuto-brasileiras eram afiliadas, via o escotismo?

O objetivo deste artigo é analisar a organização do movimento escoteiro no âmbito do associativismo ginástico teuto-brasileiro do Rio Grande do Sul, buscando compreender de que maneira estas instituições estabeleceram o diálogo entre Turnen e escotismo como formas de educação da juventude, no período compreendido entre os anos de 1913 (quando se fundou o primeiro grupo de escoteiros vinculado a uma sociedade ginástica) e 1934, quando alguns grupos escoteiros deixaram suas sociedades ginásticas, sendo substituídos por um novo 
departamento denominado Turnerjugend (“juventude ginástica”).

O corpus documental desta pesquisa é composto por distintas publicações das próprias sociedades ginásticas teuto-brasileiras do Rio Grande do Sul, artigos em jornais em língua alemã que circulavam pelo estado e fotografias. Considerando que estas instituições apresentavam forte ligação com sua terra de origem, sendo filiadas à Deutsche Turnerschaft e buscando manterse atualizadas a respeito dos caminhos que a ginástica tomava neste país, utilizamo-nos também do Deutsche Turnzeitung, órgão oficial da Deutsche Turnerschaft e que circulava entre as sociedades ginásticas teuto-brasileiras (QUITZAU, 2016), para tentar compreender de que maneira as sociedades ginásticas da Alemanha se relacionavam com o movimento escoteiro. $\mathrm{O}$ levantamento de fontes sobre o associativismo teuto-brasileiro foi realizado em distintos arquivos públicos e privados brasileiros e alemães, sendo que a documentação referente especificamente ao tema do presente artigo foi encontrada nas seguintes instituições: Instituto Martius-Staden (São Paulo); Museu Histórico Visconde de São Leopoldo (São Leopoldo/RS); Bibliothek des Instituts für Sportwissenschaft (Münster/Alemanha); Zentralbibliothek der Deutschen Sporthochschule Köln (Colônia/Alemanha); Deutsche National Bibliothek (Leipzig/Alemanha) e Bibliothek des Ibero-Amerikanisches Instituts Preußischer Kulturbesitz (Berlim/Alemanha).

\section{GINÁSTICA, VIDA AO AR LIVRE E ESCOTISMO}

No ano de 1913, o então responsável pela ginástica da Turnerbund Porto Alegre, Georg Black, viajou para a Alemanha para acompanhar dois eventos de grandes proporções que ocorreram na cidade de Leipzig: a Deutsches Turnfest, organizada periodicamente pela Deutsche Turnerschaft, e a inauguração do monumento construído em celebração ao centenário da "batalha dos povos", que colocara fim ao domínio napoleônico sobre vários territórios europeus. Ao retornar ao Brasil, Black trazia consigo uma novidade que rapidamente se 
engajou para colocar em prática em sua associação: o escotismo.

A Alemanha visitada por Black era um cenário em que um ideário de vida ao ar livre e exercícios junto à natureza perpassavam os discursos médicos e educativos veiculados por distintos grupos. Segundo Williams (2007) e Huerkamp (1986), neste período se desenvolvia no país um movimento naturista baseado nas ideias da chamada Lebensreform (reforma da vida), cujo principal objetivo era funcionar como um contraponto à sociedade urbano-industrial, aproximando os indivíduos de formas de vida mais naturais a partir de práticas que variavam desde a abstinência de álcool e nicotina até a adoção de hábitos como o nudismo e as curas naturais.

Segundo Williams (2007), surgiram neste cenário alguns movimentos que se dedicavam a atividades junto à natureza, como os Wandervogel, e que tinham como principal objetivo o cultivo da juventude (Jugendpflege). Em meio a estes grupos, surgiram algumas organizações específicas, como a Liga Jovem Alemã (Jungdeutschlandbund) e a Liga Alemã de Escoteiros (Deutscher Pfadfinderbund - D. P. B.), ambas fundadas em 1911.

Uma das principais atividades realizadas por estes grupos eram as caminhadas na natureza, realizadas pelos Wandervogel, escoteiros e mesmo pelos ginastas. A partir dessa noção de cultivo da juventude, estes grupos viam nas caminhadas uma oportunidade de afastar os jovens dos vícios da sociedade urbano-industrial, ensinar-lhes a controlar seus desejos e, também, conhecer as diversas regiões de seu país (WILLIAMS, 2007). Especialmente esta ideia de conhecer o país por meio das caminhadas não era uma novidade, mas pode ser remontada, ao menos, até os escritos de Jahn, que em seu primeiro livro, Deutsches Volkstum (1810), defendia a realização das chamadas "caminhadas patrióticas" (vaterländische Wanderungen) como uma forma de possibilitar aos indivíduos entrar em contato com outros conterrâneos e aprofundar seus conhecimentos sobre seu país.

Um ideário de vida ao ar livre e a noção de cultivo da juventude, portanto, faziam-se presente no âmbito do associativismo ginástico. Nas primeiras décadas 
do século XX, o Deutsche Turnzeitung, principal veículo de informação deste movimento, passou a trazer em seus jornais uma sessão denominada justamente Jugendpflege (cultivo da juventude), que reunia artigos relacionados aos exercícios físicos e a juventude. Nela é possível encontrar algumas referências a estes outros grupos que se dedicavam ao cultivo da juventude a partir de um retorno à natureza, como os Wandervogel e os escoteiros.

Considerando-se que as sociedades ginásticas teuto-brasileiras buscavam seguir os mesmos rumos que suas congêneres alemãs e manter-se atualizadas com as mudanças no âmbito do Turnen, se poderia pensar que uma aproximação entre sociedades ginásticas e escotismo estivesse se criando no período, uma vez que os ginastas, paulatinamente, estavam incorporando outras práticas, como os esportes. Ao consultarmos o Deutsche Turnzeitung, percebemos que as poucas menções ao escotismo são, em geral, pequenas notas sobre suas atividades. Entretanto, o primeiro e único extenso artigo publicado sobre o tema não apresentava uma postura favorável a este movimento.

Assinado por A. Rößner, um professor de ginástica de Leipzig, o artigo, publicado em dezembro de 1909, faz uma análise do manual de escotismo que acabara de ser lançado no país, intitulado Das Pfadfinderbuch e assinado pelo médico Alexander Lion, em colaboração com outros três autores, entre eles, um professor de ginástica. Segundo Rößner, todos os interessados no cultivo da juventude deveriam buscar informações sobre as novidades referentes ao tema, e o escotismo era uma dessas novidades. O livro seria inspirado na obra de Baden Powell e apresentava uma organização dos escoteiros alemães segundo o modelo inglês.

Rößner tece uma análise minuciosa, reconhecendo que apresenta um bom conteúdo, mas concentrando-se especialmente naquilo que considera como "fraquezas internas" do sistema, desde exemplos usados pelos autores e considerados por ele como "banalidades bastante superficiais" até questões mais profundas, como a própria operacionalidade da proposta que, ao apresentar uma alta demanda de tempo de preparação das atividades, assim como dos próprios 
indivíduos para liderar os grupos, se tornaria inviável. Contudo, o principal foco das críticas de Rößner recai sobre o fato de que, para um sistema que se propunha "como grande tarefa 'formar homens no melhor sentido da palavra' e 'preencher as lacunas na educação corporal de jovens entre 14 e 18 anos' " (RÖßNER, 1909, p. 917), faltava na proposta, justamente, o exercício do corpo. Afirma que

\begin{abstract}
a arte da observação, a vida no campo, o serviço de campo, também não são suficientes, para preencher essa lacuna na educação corporal entre 14 e 18 anos de idade. Os órgãos do corpo não tiram muito proveito disso, especialmente se pensamos que os exercícios não podem ser feitos com muita frequência e regularidade. As lacunas são preenchidas quando o escoteiro aprende, "em terras civilizadas, a diferenciar entre rastros de homens, animais e bicicletas e, a partir disso, concluir quem passou por aqui ou há quanto tempo", [...] ou sinaliza por meio de bandeiras, fogo ou fumaça? Isso não é mais uma educação cultural, isso pertence às escolas profissionais para detetives e guardas florestais (RÖßNER, 1909, p. 920).
\end{abstract}

Há ainda outro aspecto vinculado à questão da educação corporal que incomoda o autor e que, talvez, seja a principal razão para sua aparente oposição a este novo sistema. Ao entenderem que "toda organização existente pode, sem grandes mudanças, introduzir o sistema escoteiro entre suas aspirações” e afirmarem existir uma lacuna na formação corporal da juventude alemã, apontando para o sucesso da organização inglesa, os autores de Das Pfadfinderbuch estariam ignorando o trabalho realizado pela Deutsche Turnerschaft ao longo dos anos (RÖßNER, 1909, p. 918). Para Rößner, não haveria sentido em inserir o escotismo no cotidiano das sociedades ginásticas, uma vez que os bons exercícios deste sistema (como aprender a aferir distâncias e alturas, orientar-se por mapas e estrelas, princípios de primeiros socorros, entre outros) poderiam ser ensinados nas caminhadas junto à natureza que já faziam parte das atividades dos ginastas, de forma a "ampliar a tarefa da educação corporal, sem com isso abandonar os ideais ginásticos” (RÖßNER, 1909, p. 920). Somente nesse sentido seria indicada uma aproximação com o escotismo.

Conforme Bowersox (2013), Das Pfadfinderbuch teve uma nova edição 
em 1911, na qual os autores, entre outras alterações, "também reescreveram a genealogia do movimento para enfatizar suas origens alemãs. De acordo com eles, a história dos escoteiros não começou com Baden-Powell em Mafeking, mas com o herói nacionalista Turnvater Ludwig Jahn, na 'bela primavera do ano 1810' " (BOWERSOX, 2013, p. 199, grifo do autor). Talvez essa tentativa de aproximar as figuras de Jahn e Baden-Powell tenha contribuído para uma aproximação entre escotismo e Turnen. Exceto pelo artigo de Rößner, as outras notas encontradas são neutras ou positivas, trazendo alguns dados sobre o crescimento do movimento escoteiro em algumas regiões, indicando o lançamento de literatura sobre o tema ou anunciando sua participação em assembleias próprias ou relacionadas ao movimento de cultivo da juventude. Destaca-se, entretanto, uma nota, de 20 de março de 1913, em que a Turnverein München von 1860 anuncia a incorporação do grupo de escoteiros do Dr. Nägele a sua sociedade e afirma que "os escoteiros na Turnverein München von 1860, a partir de agora, serão educados em exercícios corporais como o Turnen, esgrima e natação" (PFADFINDER..., 1913, p. 229).

Foi a partir deste quadro de influências, portanto, que Georg Black entrou em contato com o movimento escoteiro na Alemanha, em 1913. O fato de que, em geral, os registros encontrados em nossos documentos apontam para uma relação cordial entre escoteiros e sociedades ginásticas, mas não para uma incorporação dos primeiros pelos últimos, somado à ausência de referências ao tema em outros trabalhos sobre o associativismo ginástico 4 , reforçam a ideia de que a formação de grupos escoteiros dentro de sociedades ginásticas alemãs tenha sido um fenômeno particular do caso teuto-brasileiro ou, mais especificamente, riograndense.

Logo ao retornar a Porto Alegre, Black passou a se reunir com um pequeno grupo de cerca de 5 meninos, aos domingos à tarde, para a realização de atividades escoteiras na praça de jogos da Turnerbund. Poucos anos após o início

4 Refiro-me aqui às pesquisas de Hofmann (2001; 2015) e Temme (2000). O único trabalho a mencionar uma relação entre escoteiros e sociedades ginásticas é o de Wieser (1991), que estudou justamente as sociedades ginásticas teuto-brasileiras até a Primeira Guerra Mundial. 
deste grupo de escoteiros, encontramos também menções a um grupo em Taquara, que inclusive teria uma publicação própria, intitulada Der Pfadfinder (PFADFINDERKORPS, 1915), e a grupos em São Leopoldo e São Sebastião do Caí5 (BLACK, 1915). Estas associações formaram, em 26 de janeiro de 1917, a Deutschbrasilianische Pfadfinderbund für Rio Grande do Sul (Liga de Escoteiros Teuto-brasileiros do Rio Grande do Sul), filiando-se no mesmo ano à já mencionada Deutsche Pfadfinderbund, onde passaram a conformar o Landesgruppe Rio Grande do Sul des D. P. B. (Grupo Regional Rio Grande do Sul da D. P. B.). Em 1917 é mencionada também a existência de um grupo em Santa Cruz do Sul, mas não vinculado à sociedade ginástica (KOLFHAUS, 1917) e, anos mais tarde, em nota sobre um encontro realizado em Lajeado, também sabemos da existência de um grupo nesta cidade (PFADFINDER, 1927). O que não fica claro, neste caso, é se este grupo também era vinculado à sociedade ginástica ou se funcionava em outros espaços.

Um importante indício para compreendermos as relações entre escotismo e sociedades ginásticas é um artigo publicado na Deutsche Turnblätter de janeiro de 1917. Assinado por Kolfhaus, diretor da Liga de Escoteiros TeutoBrasileiros do Rio Grande do Sul, apresenta quatro princípios que deveriam nortear esta colaboração, comentando-os um a um. O primeiro deles diz respeito justamente à vinculação dos grupos escoteiros às sociedades ginásticas. Conforme o artigo, estes grupos deveriam ser subdepartamentos autônomos dentro das sociedades ginásticas, o que lhes garantiria a possibilidade de trabalhar em segurança. Num período em que, devido à eclosão da Primeira Guerra, ganhava mais força a ideia de um "perigo alemão", "colocá-las como departamentos de instituições que não são consideradas politicamente suspeitas" (KOLFHAUS, 1917, p. 5) seria uma forma de assegurar que pudessem seguir com

\footnotetext{
5 Embora já se faça referência à existência de escoteiros em São Sebastião do Caí em 1915, em documento manuscrito encontrado no Instituto Martius-Staden (São Paulo), sobre diferentes aspectos da história dessa sociedade ginástica, afirma-se que, ainda que "muito antes de nossa sociedade possuir um grupo de escoteiros organizados, já se podia encontrar atividades escoteiras regulares dos ginastas", foi somente em uma assembleia de 1917, a partir de uma proposta do senhor Kusminsky que fora "aceita com alegria" por todos os presentes, que se formou um grupo escoteiro local (PFADFINDERGRUPPE, [1938-]).
} 
suas ações.

A ideia de um "perigo alemão" não era novidade da Primeira Guerra. Ao contrário, já circulava no Brasil desde o fim do século XIX, alimentada pelo relativo isolamento deste grupo em núcleos coloniais organizados, nos quais esforçavam-se para manter seus costumes e sua língua, e pela ideia de que um dos objetivos da política expansionista de Otto von Bismarck seria a anexação destes territórios de colonização germânica. Esta noção pode ser encontrada, por exemplo, no livreto publicado em 1906 por Sylvio Romero, intitulado $O$ Allemanismo no sul do Brasil: seus perigos e meios de o conjurar. Quando Brasil e Alemanha se colocam em lados opostos na guerra, ela retorna com força, passando a fazer parte das preocupações cotidianas das sociedades ginásticas. Aparece, por exemplo, em 1915, quando Black se pergunta:

\footnotetext{
Por que não podemos juntar um dia milhares de meninos teutobrasileiros para exercícios coletivos com culto campal, exercícios de escotismo e festa no final da tarde? O discurso do "Perigo Allemão" deveria nos assustar? Nós trabalhamos pelo melhor da pátria, Brasil, educando cidadãos hábeis, mesmo quando queremos nos manter alemães em sentimento (BLACK, 1915, p. 75).
}

A juventude era uma categoria de grande importância para estas associações, pois significava a continuidade dos trabalhos de manutenção do Turnen e da germanidade em terras brasileiras. Para um grupo que buscava atingir a maior quantidade possível de jovens para educá-los segundo seus ideais, atuando, por exemplo, em parceria com as escolas alemãs de suas colônias, a existência de outro grupo com objetivos similares poderia colocar em risco seus trabalhos e sua esfera de influências. Assim, permitir que os escoteiros se desenvolvessem em seu interior era uma alternativa a mais para atuar diretamente na educação de crianças e jovens e eliminava um rival em potencial no que diz respeito ao cultivo da juventude, evitando que "ambos danifiquem profundamente uns aos outros" (KOLFHAUS, 1917, p. 5). 
Os outros três princípios expostos por Kolfhaus também dizem respeito às questões burocráticas desta relação. Da existência como subdepartamento das sociedades ginásticas resultava que os escoteiros tinham direito de permanência nas dependências destas associações; que o líder do departamento tinha vaga na diretoria, com direito a voto; que a sociedade ginástica tinha direito a acionar o departamento para auxiliar em seus eventos festivos; e que "alunos das escolas somente podem participar do Departamento de Meninos da associação se forem escoteiros. Os escoteiros continuam a fazer parte do Departamento de Meninos" (KOLFHAUS, 1917, p. 6).

O estabelecimento da participação no Departamento de Escoteiros para que os alunos das escolas pudessem fazer parte, também, do Departamento de Meninos dessas associações nos indica o lugar que o sistema escoteiro começava a ocupar nestas instituições como um meio de educação da juventude. Ao que parece, os responsáveis por este movimento escoteiro compartilhavam da ideia de que o escotismo deveria ser um complemento à educação escolar, noção que aparece claramente em artigo publicado na Deutsche Turnblätter de agosto de 1915, assinado por Dr. Bohlen, de Münster, Alemanha.

De acordo com Dr. Bohlen, o trabalho escolar não poderia ser prejudicado pelo escotismo, e este deveria funcionar como um complemento, um apoio ao primeiro, unindo os conhecimentos e capacidades oferecidos pela escola e promovendo uma instrução saudável e o fortalecimento da honra (BOHLEN, 1915, p. 43). O escotismo poderia ser um aliado da instituição escolar, pois

ensina um olhar consciente e uma observação individual clara, oferecendo com isso pontos de partida para algumas disciplinas: ciências naturais e geografia [...] Muito marcado é o uso do escotismo como base sobre a qual se apoia o sucesso da aula. [...]

O escotismo também interfere favoravelmente em outro ponto: a luta contra o alcoolismo [...] (BOHLEN, 1915, p. 44).

Complemento ao ensino escolar e proteção contra os vícios, 
nomeadamente o alcoolismo. Estes aspectos não são criação de Bohlen ou uma particularidade do escotismo vinculado ao associativismo ginástico, mas circulavam já nos primeiros escritos de Baden-Powell, em que a natureza emergia como um espaço que libertaria de todos os males e permitiria um aprendizado concreto, a partir da prática (HEROLD JUNIOR; VAZ, 2012; MÉNDEZ; SCHARAGRODSKY, 2016). Também não são uma novidade em relação ao próprio movimento ginástico, uma vez que estas mesmas associações justificavam as atividades junto à natureza, especialmente as caminhadas, como importantes contrapontos à vida nos corrompidos ambientes urbanos. O que merece nossa atenção, todavia, é que em nenhum momento em nossas fontes se menciona Baden-Powell ou seus escritos como referencial para o movimento escoteiro. Os textos são de autoria de membros das próprias sociedades ginásticas ou, no caso do Dr. Bohlen, de autoridades alemãs.

Tendo em vista o desejo das sociedades ginásticas de atingir o maior número possível de jovens teuto-brasileiros, o terceiro princípio exposto por Kolfhaus garantia que os membros do Departamento de Escoteiros não precisavam ser associados ou filhos de sócios da sociedade ginástica. Somente caso o Departamento escolhesse como líder alguém que não fosse membro da sociedade ginástica, este deveria afiliar-se imediatamente. Por fim, segundo estes princípios básicos, se houvesse qualquer conflito entre sociedade ginástica e departamento de escoteiros, deveria ser resolvido por uma comissão composta por membros da diretoria da Turnerschaft von Rio Grande do Sul ${ }^{6}$ e da Deutschbrasilianische Pfadfinderbund für Rio Grande do Sul (KOLFHAUS, 1917, p. 6).

O escotismo, assim, despontava como importante departamento destas associações, que de certa maneira deveria proteger os jovens contra os prazeres e vícios oferecidos constantemente pela cidade, esse ambiente onde

\footnotetext{
6 A Turnerschaft von Rio Grande do Sul foi a primeira organização suprarregional de ginástica criada pelos teuto-brasileiros. Fundada no final de 1895, reunia sociedades ginásticas do Rio Grande do Sul e era responsável, entre outras coisas, pela organização de festivais coletivos de ginástica e pela realização de encontros de formação entre instrutores de ginástica.
} 
o cinema e a "radiante" Rua das Praias é seu mundo. Lá, jovens senhores passeiam, rosa no buraco do botão, cigarro na boca, vestido conforme a última moda, oferecendo ao olhar, com elegância soberana, a beleza do homem, do sexo "forte". Mas para isso o habilidoso alfaiate cobriu muito bem as deficiências da natureza. Em sapatos de couro recém polidos os dedos atrofiados ficam uns sobre os outros. [...] Em poucos anos o então vivo jovem se transformou em um macaquinho da moda (BLACK, 1915, p. 77).

Se o Turnen era uma prática que desde cedo acostumaria crianças e jovens a voluntariamente "enquadrar-se e subordinar-se", que "forja seu corpo" contribuindo para transformá-los em adultos “completos” e preparados para enfrentar as lutas que a vida lhe imporia posteriormente (UNSER KINDERTURNEN, 1936), a austeridade inerente ao escotismo se tornaria um importante aliado neste ideal de educação da juventude teuto-brasileira, não apenas afastando-a dos vícios, mas reaproximando-a da germanidade que supostamente estaria perdendo pelo contato com a "forma de vida mais leve" dos brasileiros (BLACK, 1915, p. 77). Neste sentido, Turnen e escotismo compartem dessa ideia de disciplinamento e subordinação, o que fica especialmente claro quando a Turnerbund Porto Alegre afirma que, por meio do escotismo, os garotos deveriam aprender a

[...] sacrificar sua "liberdade", ao invés de ver os outros passarem ou de estragarem seu gosto e sua vista no cinema, exercitar seus corpos e espíritos no difícil serviço no ambiente externo e aprender a aguentar a queimadura do sol e a chuva, o calor e o frio! [...] Pois a mais alta lei do escotismo, "sempre pronto", deve ser provada também na vida privada, na escola e em casa (DIE PFADFINDERABTEILUNG..., 1917, p. 22).

O grupo de Porto Alegre, ao qual se refere a maioria dos documentos, se reunia todas as quartas-feiras à noite para o aprendizado das técnicas escoteiras e, aos domingos, na praça de jogos da Turnerbund (DAS PFADFINDERKORPS, 1915, p. 3). Com o propósito de educar a "juventude de origem alemã em homens hábeis, fortes e determinados" que pudessem percorrer "novos caminhos, sem desperdiçar sua força e mobilidade nos superficiais prazeres do cotidiano”, este 
departamento via nos passeios a pé e excursões um meio de ensinar os jovens a conhecer e amar a pátria que os havia acolhido (JAHRESBERICHT..., 1931, p. 22).

Ao longo dos anos o escotismo visivelmente alcançou um lugar de importância como forma de educação da juventude nas sociedades ginásticas teuto-brasileiras. Foi, portanto, um grande golpe quando, no início da década de 1930, algumas dessas sociedades, como a Turnerbund Porto Alegre e a Turnverein São Sebastião do Cahy, repentinamente perderam estes departamentos. Em manuscrito encontrado sobre a sociedade ginástica de São Sebastião do Caí, sem entrar em muitos detalhes, afirma-se que "no mês de maio [1934] foi formado em nossa sociedade ginástica um grupo de jovens ginastas, pois o escotismo fora oficialmente desintegrado em nossa associação" (PFADFINDERGRUPPE, [1938-]). Neste mesmo período observamos a dissolução, também, do grupo de escoteiros da Turnerbund Porto Alegre, sobre o qual encontramos vestígios um pouco mais detalhados.

No relatório da Turnerbund Porto Alegre, referente às atividades de 1933, reporta-se que houve uma tentativa de aproximação com "grupos de jovens de origem alemã" da cidade, mas que não ocorrera da maneira desejada. Um destes grupos estava

inclinado à cooperação e assumiu a direção geral, conforme havia colocado como condição. Lamentavelmente, a mentalidade de seu dirigente não correspondia à da Turnerbund no que diz respeito às formas de trabalho pela germanidade, que afinal de contas é também o objetivo final do departamento de escoteiros. Dirigente e grupo se afastaram da Turnerbund (BERICHT, 1934, p. 21).

No número seguinte é publicada uma carta recebida pela associação na qual se explica que o grupo que se afastara considerava que conseguiria alcançar seus ideais se trabalhasse em conjunto com a Deutsche Jungenschaft (DEUTSCHE TURNBLÄTTER, 1934). A justificativa é recebida com espanto, já 
que "o departamento tem um representante na diretoria, que a qualquer momento poderia ter exposto seus desejos e mudanças que, caso justificados, seriam levados em consideração" (DEUTSCHE TURNBLÄTTER, 1934). Em resposta à situação, a associação funda, como em São Sebastião do Caí, um novo grupo, a Turnerjugend (“juventude ginástica”). Este novo grupo herda toda a estrutura construída pelos escoteiros ao longo das duas décadas anteriores e passa a incorporar meninas entre seus membros. A Turnerjugend queria "educar indivíduos fortes e orgulhosos, que sempre cumpram seu dever com emprego de todas as forças" (TURNERJUGEND, 1935, p. 3) e, como seu antecessor, buscou formar indivíduos disciplinados, corteses, comedidos e que mantivessem uma relação de proximidade e reverência com a natureza, com o país que os acolhera e com a terra de seus antepassados.

\section{CONSIDERAÇÕES FINAIS}

Ao que parece, o movimento escoteiro vinculado às sociedades ginásticas se desenvolveu paralelamente ao escotismo brasileiro, estabelecendo periódicos próprios, afiliando-se à Deutsche Pfadfinderbund e mantendo contato com escoteiros alemães estabelecidos em outros países, como os teuto-argentinos (DEUTSCHE TURNBLÄTTER, 1917), sem que fossem encontradas em seus relatos indicações de contatos com grupos nacionais. Ademais, a ausência de referências a departamentos de escotismo em sociedades ginásticas fundadas por alemães em outros países, bem como em sua terra natal (com exceção daquela vinculada à Turnverein München von 1860), são um indicativo de que, no âmbito do associativismo teuto-brasileiro, este movimento foi uma particularidade do Rio Grande do Sul.

Ao analisarmos as relações entre sociedades ginásticas e escotismo no Rio Grande do Sul, observamos que estas se estabeleceram principalmente a partir de uma preocupação por parte destas instituições em ter sob seu controle a educação de sua juventude. A dissolução de suas relações no início dos anos de 
1930, como registrado em Porto Alegre e São Sebastião do Caí, indica o quanto o "cultivo da juventude" teuto-brasileira era uma área de disputa entre diferentes instituições nesse período, nomeadamente entre associações teuto-brasileiras e associações fundadas pelos chamados "alemães do império", que chegaram no período entre guerras e frequentemente apresentaram proximidade com o nacional-socialismo. Segundo depoimento compilado em $A 5^{a}$ Coluna no Brasil, do tenente coronel Aurélio da Silva Py, a Deutsche Jungenschaft, à qual se uniu o grupo dissidente da Turnerbund, mudou seu nome para DeutschBrasilianischer Jugendring (Juventude Teuto-Brasileira) e teria apresentado relações próximas com a Juventude Hitlerista até o momento de sua proibição. A formação de um novo departamento nas sociedades ginásticas, a Turnerjugend, com estrutura, funcionamento e finalidades similares aos escoteiros mostra que o escotismo marcou consideravelmente as formas como elas buscaram "cultivar a juventude" teuto-brasileira nas primeiras décadas do século XX.

\section{REFERÊNCIAS}

BERICHT der Pfadfinderabteilung. Deutsche Turnblätter, a. 21, n. 2-3, p. 2124, 1934 .

BLACK, Georg. Pfadfindertum und Jugenderziehung. Deutsche Turnblätter, a. 1, n. 7, p. $74-78,1915$.

BOHLEN. Schularbeit und Pfadfinderei. Deutsche Turnblätter, a. 1, n. 4, p. 43-44, 1915 .

BOWERSON, Jeff. Raising Germans in the Age of Empire: youth and colonial culture, 1871-1914. Oxford: Oxford University Press, 2013.

DAS PFADFINDERKORPS. Deutsche Turnblätter, a. 1, n. 1, p. 3, 1915.

DER PFADFINDERAUSFLUG nach Viamão. Deutsche Turnblätter, a. 7, n. 2, p. 8, 1922.

DEUTSCHE TURNBLÄTTER, a. 21, n. 4, p. 14, 1934.

DEUTSCHE TURNBLÄTTER, a. 3, n. 9, p. 60-61, 1917. 
DIE PFADFINDERABTEILUNG des Turnerbundes Porto Alegre. Festschrift zum 25 Jahre des Turner-Bund Porto Alegre, p. 21-24, 1917.

DIE T. R. G. ZUM AUSLANDE. Deutsche Turnzeitung, a. 19, n. 6, p. 10-12, 1932.

HEROLD JUNIOR, Carlos A educação corporal no Paraná através do movimento escoteiro em Guarapuava (1927-1936). Educação em Revista, Belo Horizonte, v. 27, n. 2, p. 123-150, ago. 2011. Disponível em: http://www.scielo.br/scielo.php?script=sci_arttext\&pid=S010246982011000200007\&lng=en\&nrm=iso. Acesso em: 16 jul. 2015.

HEROLD JUNIOR, Carlos. Crise, imperialismo e a história da educação do corpo no início do século XX: o geral e o específico na proposição escoteira de Robert Baden-Powell (1857-1941). Germinal: Marxismo e Educação em Debate, v. 1, p. 165-175, 2013. Disponível em:

https://portalseer.ufba.br/index.php/revistagerminal/article/view/9644. Acesso em: 16 jul. 2015.

HEROLD JUNIOR, Carlos. O escotismo, a vida urbana e a natureza na educação do corpo nas primeiras décadas do século XX. In: SOARES, Carmen Lúcia (org.). Uma educação pela natureza: a vida ao ar livre, o corpo e a ordem urbana. 1. ed. Campinas: Autores Associados, 2016. p. 141-156.

HEROLD JUNIOR, Carlos; MELO, Victor Andrade de. Escotismo e esporte: propostas de educação do corpo no Rio de Janeiro dos anos 1910-1920. Rev. Bras. Educ., Rio de Janeiro, v. 23, e230045, 2018. DOI: http://dx.doi.org/10.1590/s1413-24782018230045. Disponível em: http://www.scielo.br/scielo.php?script=sci_arttext\&pid=S141324782018000100237\&lng=en\&nrm=iso. Acesso em: 12 dez. 2018. ePub Sep. 03, 2018.

HEROLD JUNIOR, Carlos; VAZ, Alexandre Fernandez. A educação corporal em Baden Powell: o movimento escoteiro contra o intelectualismo escolar. Revista HISTEDBR On-line, Campinas, n. 47, p. 166-184, set. 2012. Disponível em: http://periodicos.sbu.unicamp.br/ojs/index.php/histedbr/article/view/864004 6/7605. Acesso em: 11 out. 2017.

HEROLD JUNIOR, Carlos; VAZ, Alexandre Fernandez. Educação corporal, escotismo e militarismo (1908-1941). Movimento, Porto Alegre, v. 21, n. 4, p. 1011-1023, out./dez. 2015. Disponível em:

http://seer.ufrgs.br/index.php/Movimento/article/view/53323. Acesso em: 30 mar. 2016. 
HEROLD JUNIOR, Carlos; VAZ, Alexandre Fernandez. Representações sobre o escotismo, o exército e a educação corporal no Brasil: um estudo a partir de teses apresentadas em Congressos Escoteiros (1922-1923). Movimento, Porto Alegre, v. 22, n. 2, p. 417-430, abr./jun. 2016. Disponível em http://seer.ufrgs.br/index.php/Movimento/article/view/57694. Acesso em: 11 out. 2017.

HOFMANN, Annette. Aufstieg und Niedergang des deutschen Turnens in den USA. Schorndorf: Hofmann, 2001.

HOFMANN, Annette. The American Turners: their past and present. Rev. Bras. Ciênc. Esporte [online], v. 37, n. 2, p. 119-127, 2015. Disponível em: http://www.scielo.br/scielo.php?script=sci_arttext\&pid=So10132892015000200119\&lng=en\&nrm=iso. Acesso em: 16 jul. 2015.

HOFMEISTER FILHO, Carlos B. Doze décadas de história. Porto Alegre: Gráfica Editora Pallotti, 1987.

HUERKAMP, Claudia. Medizinische Lebensreform Im Späten 19. Jahrhundert. Die Naturheilbewegung in Deutschland Als Protest Gegen Die Naturwissenschaftliche Universitätsmedizin. VSWG: Vierteljahrschrift Für Sozial - Und Wirtschaftsgeschichte, v. 73, n. 2, p. 158-182, 1986. Disponível em: www.jstor.org/stable/20732617. Acesso em: o9 out. 2017.

JAHN, Friedrich Ludwig. Deutsches Volkstum. Frankfurt am Main: C. Naumanns Druckerei, 1810.

JAHN, Friedrich Ludwig; EISELEN, Ernst. Die Deutsche Turnkunst zur Einrichtung der Turnplatze. Stuttgart: Verlagsdruckerei Conradi \& Co, 1967. Faksimiledruck der Ausgabe von 1816.

JAHRESBERICHT DER PFADFINDERABTEILUNG. Deutsche Turnblätter, a. 18, n. 3-4, p. 21-22, 1931.

KOLFHAUS. Pfadfinderabteilungen und Ortsturnvereine in ihrem Verhältnis zueinander. Deutsche Turnblätter, a. 3, n. 1, p. 5-6, 1917.

MÉNDEZ, Laura Marcela; SCHARAGRODSKY, Pablo Ariel. El Escautismo en la Argentina: los diferentes sentidos sobre la naturaleza y la vida al aire libre a principios del siglo XX. In: SOARES, Carmen Lucia (org.). Uma educação pela natureza: a vida ao ar livre, o corpo e a ordem urbana. Campinas: Autores Associados, 2016.

NASCIMENTO, Adalson de Oliveira. Educação e civismo: movimento escoteiro 
em Minas Gerais (1926-1930). Revista Brasileira de História da Educação, n. 7, p. 43-73, jan./jun. 2004. Disponível em: http://periodicos.uem.br/ojs/index.php/rbhe/article/view/38670. Acesso em: 27 dez. 2014.

NASCIMENTO, Jorge Carvalho do. A escola de Baden-Powell: cultura escoteira, associação voluntária e escotismo de estado no Brasil. Rio de Janeiro: Imago, 2008.

OLIVEIRA, Maria Augusta Martiarena de; MÉNDEZ, Laura Marcela. "Scoutismo mirando al sur". El origen del movimiento scout a escala comparada. Argentina y Brasil en las primeras décadas del siglo XX. Revista HISTEDBR On-line, v. 15, n. 63, p. 3-13, jun. 2015. Disponível em: https://periodicos.sbu.unicamp.br/ojs/index.php/histedbr/article/view/86411 68/8675. Acesso em: 15 out. 2017.

PFADFINDER im Turnverein München von 1890. Deutsche Turnzeitung, $n$. 12, p. 229, 20 mar. 1913.

PFADFINDER. Deutsche Turnblätter, a. 14, n. 2, p. 20-21, 1927.

PFADFINDERABTEILUNG. Deutsche Turnblätter, a. 10, n. 1, p. 25, 1925.

PFADFINDERABTEILUNG. Deutsche Turnblätter, a. 5, n. 1, p. 10-11, 1920.

PFADFINDERGRUPPE. Folhas manuscritas. [1938-].

PFADFINDERKORPS. Deutsche Turnblätter, a. 1, n. 6, p. 67-68, 1915.

PY, Aurelio da Silva. A $5^{\mathbf{a}}$ coluna no Brasil: a conspiração nazi no Rio Grande do Sul. Porto Alegre: Edição da Livraria Globo, 1942.

QUITZAU, Evelise Amgarten. Associativismo ginástico e imigração no Sul e Sudeste do Brasil (1858-1938). 2016. Tese (Doutorado em Educação) - Faculdade de Educação, Universidade Estadual de Campinas, Campinas, 2016.

QUITZAU, Evelise Amgarten. Educação do corpo e vida associativa: as sociedades ginásticas alemãs em São Paulo (fins do século XIX, primeiras décadas do século XX). 2011. Dissertação (Mestrado) - Faculdade de Educação Física, Universidade Estadual de Campinas, Campinas, 2011.

RABELO, Ricardo Rocha; BARRETO, Raylane Andreza Dias Navarro. O escotismo como associação voluntária no início do século XX: prática pedagógica extra-escolar. Interfaces Científicas - Educação, Aracajú, v. 1, n. 3, p. 33-41, jun. 2013. Disponível em: 
https://periodicos.set.edu.br/index.php/educacao/article/view/306/409. Acesso em: 12 dez. 2018.

RÖßNER, A. Das Pfadfindersystem. Deutsche Turnzeitung, n. 52, p. 917-921, 30 dez. 1909.

SELTEN, Peter. Youth movements as agencies of cultural transmission. The emergence of youth movements at the beginning of the twentieth century.

Paedagogica historica, v. 32, Issue sup. 1: Education and Cultural Transmission, p. 265-282, 1996. Disponível em:

http://www.tandfonline.com/action/showCitFormats?doi=10.1080\%2Fo03092 30.1996.11434868. Acesso em: o9 out. 2017.

SEYFERTH, Giralda. As associações recreativas nas regiões de colonização alemã no sul do Brasil: Kultur e etnicidade. Revista Travessia, n. 34, mai./ago. 1999.

SOUZA, Rosa Fátima de. A militarização da infância: expressões do nacionalismo na cultura brasileira. Cadernos Cedes, Campinas, v. 20, n. 52 , p. 104-121, nov. 2000. Disponível em:

http://www.scielo.br/scielo.php?script=sci_arttext\&pid=So101$32622000000300008 \& \operatorname{lng}=\mathrm{en} \& n r m=$ iso. Acesso em: 12 dez. 2018.

TEMME, Maik. Die deutsche Turnbewegung in Chile 1852-1945:

zwischen Identitätswahrung und Assimilation. Würzburg: Ergon Verlag, 2000.

TEUTO-BRASILIANISCHER Turnverein Curityba. Vereins-Zeitung, a. 1, n. 4, p. $8,1929$.

TURNERJUGEND. Deutsche Turnblätter, a. 22, n. 8, p. 3-4, 1935.

UNSER KINDERTURNEN. Leopoldenser Turnverein, a. 4, n. 4, p. 1, 1936.

WIESER, Lothar. Deutsches Turnen in Brasilien: Deutsche Auswanderung und die Entwicklung des deutsche-brasilianisches Turnwesen bis zum 1917. Londres: Arena Publications, 1991.

WILLEMS, Emílio. A aculturação dos alemães no Brasil. São Paulo: Companhia Editora Nacional, 1980.

WILLIAMS, John Alexander. Turning to nature in Germany: hiking, nudism and conservation, 1900-1940. Stanford: Stanford University Press, 2007. 
EVELISE AMGARTEN QUITZAU é licenciada em Educação Física pela Universidade Estadual de Campinas (Unicamp). Mestre em Educação Física e doutora em Educação pela mesma instituição. Atualmente é professora do Instituto Superior de Educación Física (Isef), Universidad de la República (Udelar), no Uruguai.

E-mail: eveliseaq@yahoo.com.br

(1) http://orcid.org/0000-0001-9789-6488

Recebido em: 29 de novembro de 2017

Aprovado em: 21 de dezembro de 2018

Revista História da Educação - RHE

Associação Sul-Rio-Grandense de Pesquisadores em História da Educação - Asphe Artigo de acesso aberto distribuído nos termos de licença Creative Commons. 